Original Article

\title{
PROCALCITONIN FOR IMPROVED ASSESSMENT AND AN ANSWER TO SEPSIS DILEM M A IN CRITICALY ILL - A MYTH, A HYPE, OR A REALITY ?
}

\author{
Raghava Sharma ${ }^{1} \&$ Maniyar Vijayakumar ${ }^{2}$ \\ ${ }^{1}$ Professor, Department of M edicine, K. S. Hegde Medical Academy, Nitte University, Deralakatte, \\ ${ }^{2}$ Ex Jr Resident, Kasturba M edical College, Mangalore, Karnataka, INDIA. \\ Correspondence \\ Raghava Sharma \\ Professor, Department of M edicine, K.S. Hegde M edical Academy, Nitte University, \\ Deralakatte, M angalore - 575018, Karnataka, India. \\ E-mail : rrsharma1967@yahoo.com
}

\begin{abstract}
:
Background and objectives: "Sepsis is a major cause for mortality in critically ill patients all over the world. The number of patients presenting with sepsis, septic shock is gradually increasing in daily clinical practice. Mortality in sepsis is mainly due to a delay in diagnosis and initiation of specific therapy(antibiotics).This is in turn mainly attributed to the difficulty in differentiating infectious trigger(sepsis) from non infectious triggers as both present with similar clinical features. Lack of specific marker adds to this dilemma of differentiating infectious and non infectiousfactors in critically ill patients.

Recently there are some reports from European countries on role of Procalcitonin (PCT) in critically ill patients. Draw backs of these studies are galore mainly due to the difficulties in interpretation of results, as varying definitions for sepsis are used. But also there is paucity of data on Procalcitonin from Indian sub continent. Hence in the present single centre prospective observational study conducted at tertiary care medical college hospital , A total of 50 adult patients with sepsis fulfilling ACCP/SCCM guidelines were included, out of which 23 were in SIRS/Sepsis, 14 in severe sepsis and 13 in septic shock. Procalcitonin was evaluated in the first 24 hours after admission and before initiation of any antibiotic therapy. The role of procalcitonin was analyzed in relation to confirming sepsis, assessing the severity of sepsis and assessing the prognosis(possible out come) of sepsis. Combined role of procalcitonin with other indicators especially ESR, SOFA Score, Blood/relevant material culture was explored.
\end{abstract}

Results: Our study confirmed the importance of procalcitonin in critically ill patients particularly in improving the predictive power while solving the sepsis dilemma.

Conclusions: From our study, we conclude that Procalcitonin is not a myth nor a hype but it is a hard reality and is an answer to sepsis dilemma. It is therefore preferable to add Procalcitonin into the standard workup of critically ill patients with suspected sepsis in every day clinical practice.

Keywords: Procalcitonin, PCT, SOFA Score, Sepsis, Septic shock, ACCP/SCCM guidelines, Sepsis dilemma

\section{Introduction :}

Sepsis refers to the systemic response to serious infection by any class of micro organism. Sepsis can be simply defined as a spectrum of clinical manifestations caused by

\begin{tabular}{|c|}
\hline Access this article online \\
\hline Quick Response Code \\
\hline
\end{tabular}

Recently there is an increase in the incidence of sepsis and septic shock mainly due to $(A)$ an increase in infections due to antibiotic resistant organisms, (B) increased use of invasive devices such as intra venous catheters, (C) wide spread use of cyto toxic and immunosuppressive drug therapies for cancer and transplantations, (D) increased life span of patients with Hiv, cancer, and diabetes who are more prone to develop sepsis ${ }^{2,3}$.

The source of infection is an important determinant of clinical outcome. The most frequent source, sites and portal of entry of micro organisms causing sepsis are genito 
urinary tract(25\%), respiratory tract and lungs(20\%), biliary tract and abdomen $(5 \%)$, and other sources being skin, soft tissue, central nervous system, miscellaneous and uncertain sites ${ }^{4}$. Patients with nosocomial pneumonia, intra abdominal infection and poly microbial bacteria are at significant risk for severe sepsis. Bacteraemia associated with intra vascular catheters or indwelling urinary catheters carries a lower risk of developing septic shock ${ }^{5,6}$.

Micro organisms that are commonly implicated in sepsis and sepsis related conditions(SIRS, Septic shock) include $S$ epidermidis, S aureus, Bacillus species, Corynebacterium species, and the organisms that contaminate hands of medical personnel such as pseudomonas aeruginosa, acinetobacter species, candida species, klebsiella, and entero bacter species ${ }^{3,7}$. Recently Gram Positive pathogens seems to have largely superseded Gram Negative pathogensin inducing sepsis ${ }^{8}$.

Sepsis is reported to be the most common cause of death in intensive care units, particularly among elderly, immunocompromised, and critically ill. Approximately 25 $35 \%$ of patients with severe sepsis and $40-45 \%$ of patients with septic shock die within 30 days ${ }^{2}$. Gram Negative bacteria cause more deaths due to sepsis ${ }^{7}$ and pathogens associated with highest mortality rate are entero bacteriaceae and $P$ aeruginosa ${ }^{8}$.

\section{Sepsis Dilemma}

Early diagnosis of sepsis is of prime and paramount importance as early institution of appropriate anti microbial therapy is associated with better outcomes. More over it also helps in avoiding wide spread and irrelevant administration of antibiotic therapy which further helps in preventing antibiotic resistance, drug toxicity, and higher cost. In some cases, history and physical examination with or without routine laboratory tests may be enough to diagnose sepsis. But it is often difficult to distinguish critically ill patients with systemic infection, sepsis, organ dysfunction or shock from patients with similar clinical signs and laboratory findings without infections ${ }^{9,10}$. Even though culture positivity for causative organism is considered to be the gold standard, microbiological evidence for infection may not develop at the same time ${ }^{11}$. Blood cultures yield bacteria or fungi in approximately $20-40 \%$ of severe sepsis cases and $40-70 \%$ of cases of septic shock ${ }^{12}$. M icrobial cultures require more time and negative results donot exclude sepsis.

\section{Rationale and Need for the Present Study}

In view of the above facts, there is an urgent need for an effective, appropriate, sensitive and specific early marker of infection to accurately solve the sepsis dilemma(diagnostic, therapeutic, and prognostic dilemma). Recently Procalcitonin(PCT) has caught the attention of researchers world wide as an interesting possible marker of systemic inflammatory response to infection, sepsis ${ }^{13}$.

PROCALCITONIN (PCT) is the 116 amino acid pro hormone of calcitonin which is normally produced in the C cells of the thyroid gland. Normally all procalcitonin is cleaved by specific proteases and none is released in to the blood stream. PCT levels are thus undetectable $(<0.1 \mathrm{ng} / \mathrm{ml})$ in healthy humans. However during severe infections with systemic manifestations, PCT levels may increase to over $100 \mathrm{ng} / \mathrm{ml}^{3}$. PCT is thus an integral part of the inflammatory response to infection ${ }^{15,16}$. The exact origin of PCT during sepsis is uncertain but probably produced by extra thyroid tissues also ${ }^{13,14}$. Study on PCT kinetics involving volunteers revealed PCT levels started to raise in 3-4 hours after insult, peaking by 14 hours and high values (of $4 \mathrm{ng} / \mathrm{ml}$ ) remaining up to 24 hours, with a half life of 25-30 hours. The same PCT kinetics is expected to occur in all sepsis and septic shocks ${ }^{14,15,16,17}$.The temporal relationship between the onset or control of infection and PCT concentrations, as well as its patho physiological role in sepsis and exact position within the inflammatory mediator cascade are poorly understood $^{8,17,18}$.

There are few studies trying to identify the role of PCT and its superiority to $c$ - reactive protein(CRP) in diagnosing and assessing the severity of sepsis . But all of them are from European or western countries ${ }^{2,13,19,20,21,22,23}$.The draw backs of these studies is the difficulties in the interpretation of results mainly due to varying definitions for the used terms 
like infection, bacteraemia, sepsis, septic shock. At the same time there is paucity of data on PCT from Indian subcontinent.

Hence the present study was undertaken to evaluate the role of PCT in effectively solving the sepsis dilemma among critically ill patients by strictly adhering to the criteria by American college of chest physicians, So ciety of critical care medicine (ACCP/SCCM ) ${ }^{24}$ and also to correlate the same to SOFA (sepsis related organ failure assessment) score ${ }^{10}$ to reinforce sepsis severity assessment.

\section{Methodology :}

The present prospective, cross sectional, observational study was undertaken in a tertiary care medical college hospital at Mangalore, coastal Karnataka after it was approved and permitted by the ethical committee of the institute. In the present study it was aimed to analyze (i) Role of PCT in diagnosing and confirming sepsis, (ii) Role of PCT in identifying severity of sepsis, (iii) Role of PCT in correlating severity of sepsis to SOFA scores, (iv) Role of PCT as a prognostic marker in sepsis and its importance in outcome and mortality. A total of 50 adult patients aged more than $18 \&$ less than 80 years who fulfilled the criteria for definition of SIRS/sepsis, severe sepsis, septic shock as defined by ACCP/SCCM (Table 1) were selected and included in the study. Patients with age $<18$ years, $>80$ years, with co morbidities like major trauma, surgery, burns and malignancy were excluded from the study as these conditions could lead to a rise in PCT levels. Detailed symptoms history and detailed physical examination was undertaken for each included patient. The patients were grouped in to the following severities namely SIRS, sepsis, severe sepsis, and septic shock in accordance with the criteria from the guidelines of ACCP/SCCM ${ }^{24}$. SOFA (sepsis related organ failure assessment score ${ }^{10}$ was calculated for all the patients included in the study as described in Table 2, and Mean score was calculated for SIRS/sepsis severe sepsis, and septic shock. PCT level was estimated by using BRAHMS PCT-Q test(technique fully described under appendix - 1 below)in all the 50 patients included in the study and was correlated and compared with SOFA score and degree of sepsis(as per ACCP/SCCM criterias).The following PCT cut offs were employed for therapeutic intervention and analysis of outcome-

PCT $<0.5 \mathrm{ng} / \mathrm{ml}$ : Local bacterial infection possible, systemic infection(sepsis) unlikely.

PCT $>0.5 \&<2 \mathrm{ng} / \mathrm{ml}$ : Suggests systemic infection(sepsis).

PCT $>2 \&<10 \mathrm{ng} / \mathrm{ml}$ : Suggests severe sepsis.

PCT $>10 \mathrm{ng} / \mathrm{ml}$ : Suggests almost exclusively septic shock.

From all the study population , for the definitive etiological diagnosis(isolation of micro organism) at least two blood samples were collected by aseptic precaution and subjected to culture. Materials from primary site of infection inclusive of urine, sputum, pleural fluid, ascetic fluid, pus were sent for Gram stain and culture. All the samples for culture were obtained immediately once sepsis was suspected, within 24 hours of admission to hospital and before starting antibiotic treatment. Other relevant lab parameters particularly Haemoglobin, White blood cell count, Platelet count, ESR, Prothrombin time, INR(international normalization ratio), Renal function test, and Liver function test were performed in all the included subjects. The data thus obtained were tabulated and then analyzed.

\section{Appendix 1:}

BRAHM S PCT-Q Test (PCT estimation technique) ${ }^{18}$ : An immuno chromatographic test for the semi quantitative detection of PCT(procalcitonin) with an incubation period of only 30 minutes, which neither depends on apparatus nor needs calibrating. The test uses a monoclonal mouse anti catacalcin antibody conjugated with colloidal gold(tracer) and a polyclonal sheep anti calcitonin antibody(solid phase). These two antibodies rules out cross reactivity. After the patient sample(serum) has been applied to the test strip, the tracer binds to the PCT in the sample and marked antigen antibody complex forms. This complex moves by means of capillarity through the test system and in the process passes through the area containing the test band. Here the marked antigen antibody complex binds to the fixed anti calcitonin 
antibodies and forms a sandwich complex. At a PCT concentration $>0.5 \mathrm{ng} / \mathrm{ml}$, this sandwich complex can be seen as a reddish band. The colour intensity of the band is directly proportional to the PCT concentration of the sample. By comparing with the reference card thus PCT concentration in the sample can be obtained as (a) $<0.5$ $\mathrm{ng} / \mathrm{ml}$, (b) $>0.5 \&<2 \mathrm{ng} / \mathrm{ml}$, (c) $>2 \&<10 \mathrm{ng} / \mathrm{ml}$, (d) $>10$ $\mathrm{ng} / \mathrm{ml}$. Non bound tracer diffuses in to the control band zone, where gets fixed and produces an intensely red coloured control band. The functional ability of the test system is checked by means of this control band.

\section{Observations and Results}

In this study, total of 50 patients were selected who were fitting in to the inclusion criteria as described in the methodology.

- Out of 50 patients, Procalcitonin was positive in 47(94\%) patients.(Fig 1)

- $52 \%$ of the study patients were males and $48 \%$ were females.(Table 3)

- Maximum number of study patients were in the age group of 51-60 years.(Fig 2, Table 4)

- Out of total 50 patients, 23(52\%)patients were in the group of SIRS/sepsis, $14(26 \%)$ patients were in group of severe sepsis, while $13(22 \%)$ were in group of septic shock.(Table5)

- Most common symptom in patients with sepsis was fever.( table 6)

- Most common signs in patients with sepsis were Tachycardia(91\%), followed by high temperature(76\%) and then tachypnoea(65\%).(Table 7)

- Among other laboratory parameters, almost all patients with sepsis had leucocytosis and high ESR. (Table 8)

- Most common identified source of sepsis was respiratory tract infection(40\%), followed by urinary tract infection(20\%).(Fig 3, Table 9)

- Increase in level of PCT was clearly evident as the severity of sepsis (as per ACCP/SCCM criterias) increased, irrespective of the source of sepsis.(Table 10, $11,12)$

- Out of total 50 patients 20(40\%) were culture positive and among those $14(70 \%)$ grew Gram negative organisms in culture. Most common Gram negative organism grown was E.Coli, while most common Gram positive organism grown was M RSA.(Fig 4, Table 13)

- Culture of Blood, Urine, Sputum, Pus, and Ascitic fluid were collectively responsible for the $40 \%$ positivity. All culture positive cases had PCT levels $>0.5 \mathrm{ng} / \mathrm{ml}$ while all culture negative cases had low PCT levels $<0.5$ ng/ml.(Table 14)

- Even in culture negative sepsis patients, high PCT levels was evident and consistent with severity of sepsis. (Fig5, Table 15)

- PCT was positive in 47 out of total 50 patients and high levels of PCT ( $>10 \mathrm{ng} / \mathrm{ml}$ ) was characteristically noted in patients with severe sepsis and septic shock.(Fig 6, Table 16)

- M Mean SOFA score was 4.9 for SIRS/ sepsis, 10.2 for severe sepsis, and 11.8 for septic shock. Thus increasing level of Mean SOFA score was clearly evident and correlated well with increasing severity of sepsis.(Table 17)

- Correlation of PCT level and M ean SOFA score clearly demonstrated a progressively increasing PCT level corresponding well to progressively increasing Mean SOFA scores. Thus PCT level and Mean SOFA scores correlated well with sepsis severity.(Table 18)

- Correlation of PCT to ESR in all the included subjects demonstrated that, although ESR was high in patients with sepsis, it did not correlate well with severity of sepsis.(Table 19)

- All sepsis patients who had mortality had very high PCT level ( $>10 \mathrm{ng} / \mathrm{ml}$ ) at the time of admission.(Fig 7, Table 20) 
FIGURE 1: Procalcitonin positivity

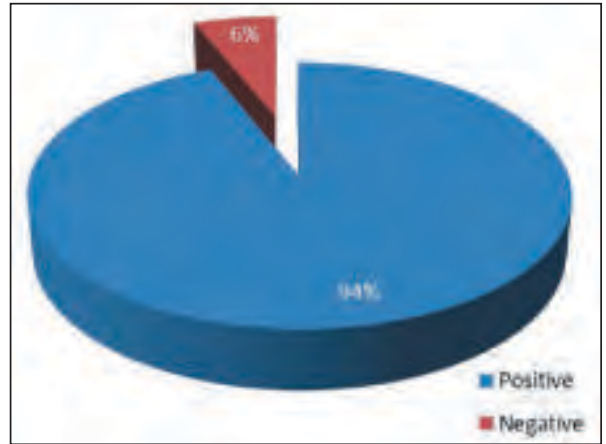

FIGURE 2 : Age distribution.

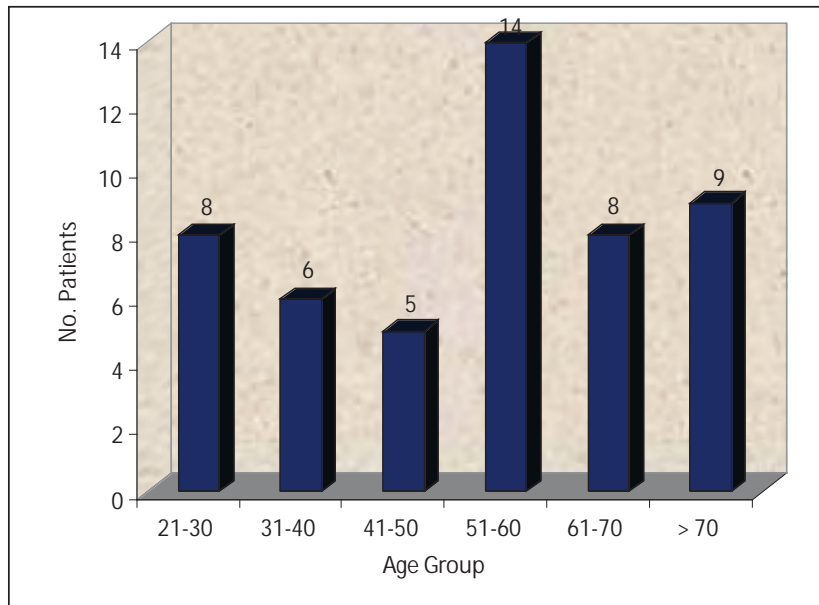

FIGURE 3 : Source of sepsis.

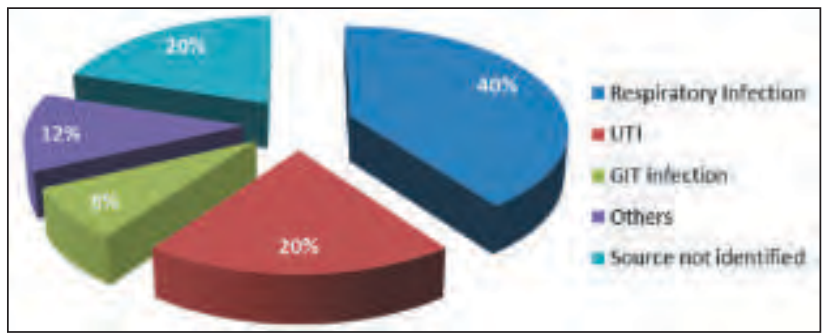

FIGURE 4 : Organism grown in culture.

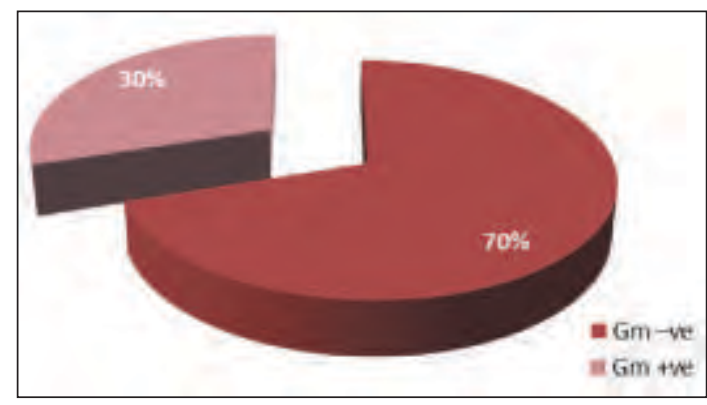

FIGURE 5 : Culture and PCT in relation to severity of sepsis.

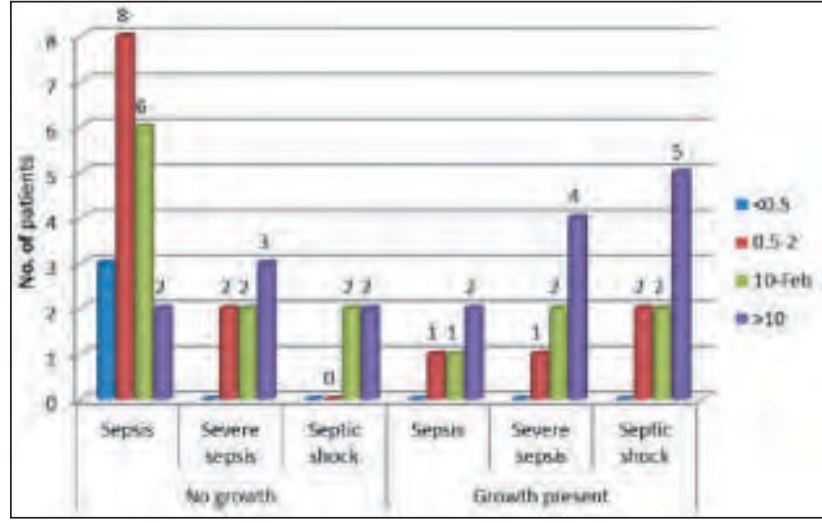

FIGURE 6 : Diagnostic value of PCT for severity of sepsis.

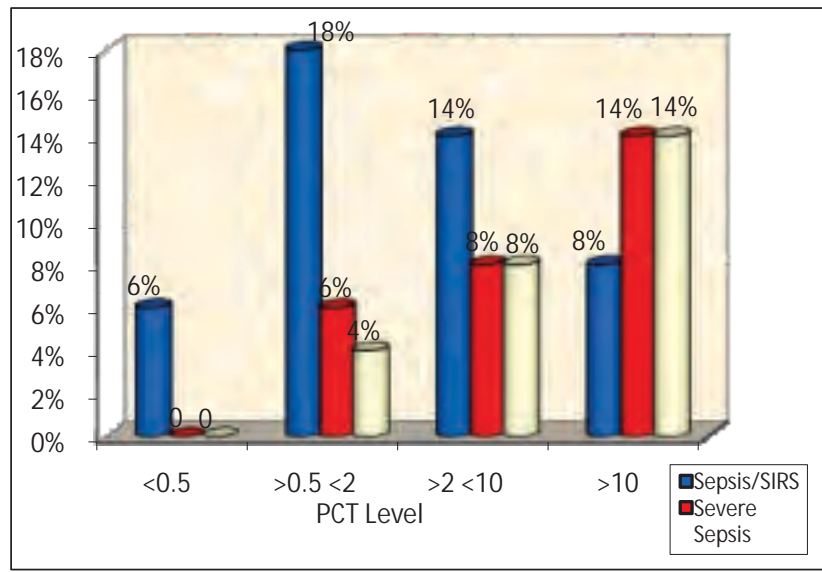

FIGURE 7 : PCT Vs Mortality.

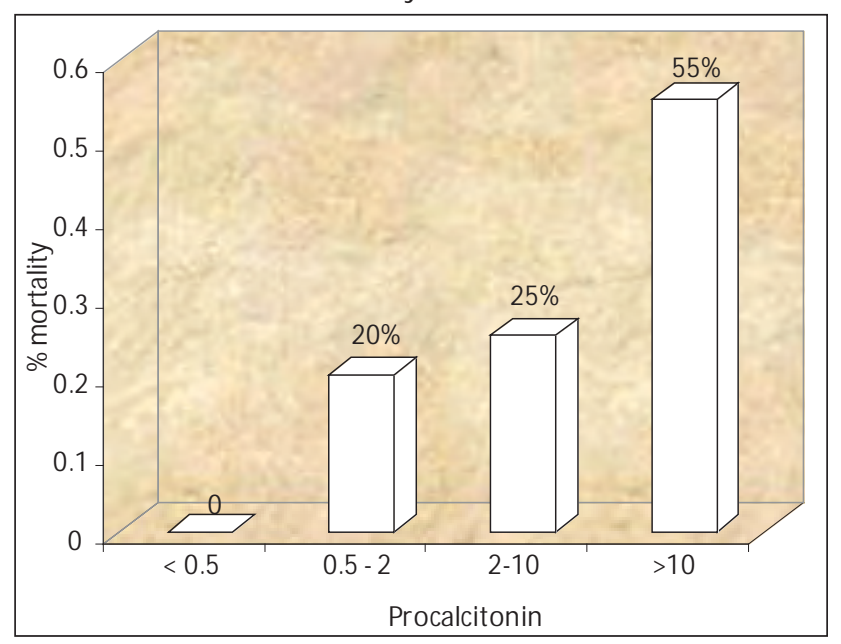


TABLE 1 : ACCP/SCCM CONSENSUS GUIDELINES ${ }^{24}$

\begin{tabular}{|c|c|}
\hline CLINICALSTATUS. & CONSENSUSGUIDE LINES/CRITERIAS \\
\hline A. Infection & $\begin{array}{l}\text { Microbial phenomenon characterized by an inflammatory response to } \\
\text { the presence of micro organism or the invasion of normally sterile host } \\
\text { tissueby those organisms. }\end{array}$ \\
\hline B. Bacteraemia & $\begin{array}{l}\text { The presence of viable bacteria in the blood as evidenced by positive } \\
\text { blood culture. }\end{array}$ \\
\hline C. Systemic inflammatory response syndrome (SIRS) & $\begin{array}{l}\text { The systemic inflammatory response to a variety of insults, manifested } \\
\text { by two or more of the following: } \\
\text { (i) Temperature }>38^{*} \mathrm{C} \text { or }<36 * \mathrm{C} \\
\text { (ii) Heart rate }>90 \text { beats/minute } \\
\text { (iii)Respiratory rate }>20 \text { breaths/min or } \mathrm{PaC} 02<32 \mathrm{mmHg} \\
\text { (iv)White blood cell count }>12000 / \text { cu } \mathrm{mm},<4000 / \mathrm{cu} \mathrm{mm},>10 \% \\
\text { immature forms. }\end{array}$ \\
\hline D. Sepsis & $\begin{array}{l}\text { SIRS Plus suspected or documented infection site by positive culture for } \\
\text { the organism from that site. }\end{array}$ \\
\hline E. Severe sepsis & $\begin{array}{l}\text { Sepsis with one or more signs of organ dysfunction- } \\
\text { (i) Cardiovascular: Arterial systolic blood pressure }<90 \mathrm{mmHg} \text { or } \\
\text { Mean arterial pressure }<70 \mathrm{mmHg} \text { that responds to } \\
\text { administration of intravenous fluids, Pulmonary artery wedge } \\
\text { pressure }>12 \mathrm{mmHg} \text { or central venous pressure }>8 \mathrm{mmHg} \text { after } \\
\text { adequate fluid resuscitation. } \\
\text { (ii) Renal: Urine output }<0.5 \mathrm{ml} / \mathrm{kg} \text { per hour for } 1 \text { hour despite } \\
\text { adequate fluid resuscitation. } \\
\text { (iii) Respiratory: Pao2/Fio } 2<250 \text { or }<200 \text { if lung is the only } \\
\text { dysfunctional organ. } \\
\text { (iv) Haematological: Platelet count }<80000 / \mathrm{mcL} \text { or } 50 \% \text { decrease in } \\
\text { platelet count from highest value recorded over previous } 3 \text { days. } \\
\text { (v) Metabolic acidosis: Ph }<7.3 \text { or a base deficit }>5 \& \text { plasma lactate } \\
\text { level }>1.5 \text { timesupper limit of normal for reporting lab. }\end{array}$ \\
\hline F. Septicshock & $\begin{array}{l}\text { Sepsis with hypotension despite adequate fluid resuscitation, along } \\
\text { with presence of perfusion abnormalities that may include lactic } \\
\text { acidosis, oliguria, or an acute alteration in mental status. }\end{array}$ \\
\hline G. Refractory septic shock & $\begin{array}{l}\text { Septic shock that lasts for more than } 1 \text { hour and does not respond to } \\
\text { fluid or vaso pressor administration. }\end{array}$ \\
\hline
\end{tabular}

Table 2 : SOFA SCORING SYSTEM ${ }^{10,25}$

By European Society of Intensive Care M edicine in 1994. Six organ systems/variables evaluated in a scale of 0- 4 each. The arithmetical sum of these six is the value of SOFA score.

\begin{tabular}{|c|c|c|c|c|c|}
\hline \multicolumn{6}{|c|}{ SOFA Score } \\
\hline Variable & 0 & 1 & 2 & 3 & 4 \\
\hline Respiratory -PaO2/FiO2 mmHd & $>400$ & $301-400$ & $201-300$ & $101-200$ & $\leq 100$ \\
\hline $\begin{array}{l}\text { Coagulation - Platelet } \\
\text { ( lakh / dl ) }\end{array}$ & $\begin{array}{l}<1.2 \\
(<20)\end{array}$ & $\begin{array}{c}1.2-1.9 \\
(20-32)\end{array}$ & $\begin{array}{c}2.0-5.9 \\
(33-100)\end{array}$ & $\begin{array}{c}6.0-11.9 \\
(101-203)\end{array}$ & $\begin{array}{c}>12 \\
(>203)\end{array}$ \\
\hline $\begin{array}{l}\text { Hepatic -Bilirubin, } \\
\mathrm{mg} / \mathrm{dL}(\mu \mathrm{mol} / \mathrm{L})\end{array}$ & $\begin{array}{l}<1.2 \\
(<20)\end{array}$ & $\begin{array}{c}1.2-1.9 \\
(20-32)\end{array}$ & $\begin{array}{c}2.0-5.9 \\
(33-100)\end{array}$ & $\begin{array}{c}6.0-11.9 \\
(101-203)\end{array}$ & $\begin{array}{c}>12 \\
(>203)\end{array}$ \\
\hline CVS - Hypotension & $\begin{array}{c}\mathrm{MABP}>70 \\
\mathrm{mmHg}\end{array}$ & $\begin{array}{l}\text { MABP }<70 \mathrm{mmHg} \\
\text { without ionotropes }\end{array}$ & Dop $\leq 5$ & $\begin{array}{c}\text { Dop } 6-15 \text { or } \\
\text { Epi } \leq 0.1 \text { or } \\
\text { Norepi } \leq 0.1\end{array}$ & $\begin{array}{l}\text { Dop }>15 \text { or } \\
\text { Epi }>0.1 \text { or } \\
\text { Norepi }>0.1\end{array}$ \\
\hline CNS - Glasgow Coma Score & 15 & $13-14$ & $10-12$ & $6-9$ & $<6$ \\
\hline $\begin{array}{l}\text { Renal - Creatinine, } \\
\mathrm{mg} / \mathrm{dL}(\mu \mathrm{mol} / \mathrm{L})\end{array}$ & $\begin{array}{l}<1.2 \\
(<106)\end{array}$ & $\begin{array}{c}1.2-1.9 \\
(106-168)\end{array}$ & $\begin{array}{c}2.0-3.4 \\
(169-300)\end{array}$ & $\begin{array}{c}3.5-4.9 \\
(301-433)\end{array}$ & $\begin{array}{c}>5 \\
(>434) \\
\text { or anuria }\end{array}$ \\
\hline
\end{tabular}

M ABP - M ean Arterial Blood Pressure, Dop-Dopamine Epi-Epinephrine Norepi - Norepinephrine SOFA score $>13$ is associated with high mortality. 
Table 3: Sex Distribution

\begin{tabular}{|c|c|c|}
\hline Sex & No. Patients $(n=50)$ & Percentage \\
\hline Male & 26 & $52 \%$ \\
\hline Female & 24 & $48 \%$ \\
\hline
\end{tabular}

Table 4: Age distribution

\begin{tabular}{|c|c|c|}
\hline Age group & No. Patients & Percentage \\
\hline $21-30$ & 8 & 16 \\
\hline $31-40$ & 6 & 12 \\
\hline $41-50$ & 5 & 10 \\
\hline $51-60$ & 14 & 28 \\
\hline $61-70$ & 8 & 16 \\
\hline$>70$ & 9 & 18 \\
\hline
\end{tabular}

Table 5: Severity of sepsis

\begin{tabular}{|c|c|c|}
\hline Sepsis & No. Patients $(n=50)$ & Percentage \\
\hline Sepsis / SIRS & 23 & 52 \\
\hline Severe sepsis & 14 & 26 \\
\hline Septic shock & 13 & 22 \\
\hline
\end{tabular}

Table 6: Frequency of symptoms in patients

\begin{tabular}{|l|c|}
\hline Symptoms & Percentage(\%) \\
\hline Fever & 83 \\
\hline Chills & 15 \\
\hline Cough & 40 \\
\hline Breathlessness & 35 \\
\hline Altered Sensorium & 32 \\
\hline Vomiting & 21 \\
\hline Loose stools & 13 \\
\hline Pain abdomen & 12 \\
\hline Jaundice & 7 \\
\hline Headache & 6 \\
\hline Burning micturition & 6 \\
\hline Swelling of lower limb & 6 \\
\hline Seizures & 3 \\
\hline
\end{tabular}

Table 7: Frequency of Common Signs in Patients

\begin{tabular}{|l|c|}
\hline Signs & Percentage \\
\hline Febrile-High temperature & 76 \\
\hline Tachycardia & 91 \\
\hline Tachypnoea & 65 \\
\hline Hypotension & 37 \\
\hline Pallor & 43 \\
\hline Edema & 33 \\
\hline Icterus & 30 \\
\hline Altered sensorium & 30 \\
\hline petechiae & 7 \\
\hline Subconjunctival hemorrhage & 6 \\
\hline Lymphadenopathy & 2 \\
\hline
\end{tabular}

Table 8: Other Lab parameters

\begin{tabular}{|l|c|}
\hline Lab parameters & Percentage \\
\hline Decreased Hemoglobin $(<10 \mathrm{gm} \%)$ & 49 \\
\hline Leucoytosis $(>12,000)$ & 78 \\
\hline Leucopenia $(<4,000)$ & 6 \\
\hline Thrombocytopenia $(<1,50,000)$ & 55 \\
\hline Prolonged PT/INR & 47 \\
\hline Altered RFT & 67 \\
\hline Altered LFT & 50 \\
\hline Raised ESR & 73 \\
\hline
\end{tabular}

Table 9: Source of sepsis

\begin{tabular}{|l|c|}
\hline Respiratory Tract Infection & $20(40 \%)$ \\
\hline Urinary tract infection & $10(20 \%)$ \\
\hline Gastro intestinal tract infection & $5(10 \%)$ \\
\hline Others & $5(10 \%)$ \\
\hline Source not identified & $10(20 \%)$ \\
\hline
\end{tabular}

Table 10: Relationship between procalcitonin and sepsis in respiratory tract infection

Total no. of respiratory tract infections $=20(40 \%, n=50)$.

\begin{tabular}{|l|c|c|c|}
\hline Procalcitonin $(\mathrm{ng} / \mathrm{ml})$ & Sepsis & Severe sepsis & Septic shock \\
\hline$<0.51$ & - & - & \\
\hline$>0.5<2$ & 4 & 1 & 1 \\
\hline$>2<106$ & - & 1 & \\
\hline$>10 \quad 3$ & 1 & 2 & \\
\hline
\end{tabular}

Table 11: Relationship between procalcitonin and sepsis in Urinarytract infections.

Total no. of patients with UTI $=10(20 \%, n=50)$.

\begin{tabular}{|l|c|c|c|}
\hline Procalcitonin (ng/ ml) & Sepsis & Severe sepsis & Septic shock \\
\hline$<0.5$ & 1 & 0 & 0 \\
\hline$>0.5<2$ & 2 & 0 & 1 \\
\hline$>2<10$ & 1 & 0 & 1 \\
\hline$>10$ & 2 & 1 & 1 \\
\hline
\end{tabular}

Table 12: Relationship between procalcitonin and sepsis in gastro intestinal tract infections

Total no. of patients with GIT infections $=5(10 \%, n=50)$.

\begin{tabular}{|l|c|c|c|}
\hline Procalcitonin (ng/ ml) & Sepsis & Severe sepsis & Septic shock \\
\hline$<0.5$ & 0 & 0 & 0 \\
\hline$>0.5<2$ & 1 & 0 & 0 \\
\hline$>2<10$ & 1 & 1 & 1 \\
\hline$>10$ & 1 & 0 & 0 \\
\hline
\end{tabular}

Table 13: Organism grown in culture Total number of positive cultures $=20(40 \%)$.

\begin{tabular}{|c|c|}
\hline $\mathrm{Gm}-\mathrm{ve}$ & $14(70 \%)$ \\
\hline $\mathrm{Gm}+\mathrm{ve}$ & $6(30 \%)$ \\
\hline
\end{tabular}


Table 14: Relationship between procalcitonin and cultures in patients with sepsis

Total no. of positive cultures $=20(40 \%)$

\begin{tabular}{|l|c|c|c|c|c|}
\hline $\begin{array}{l}\text { Procalcitonin } \\
\text { (ng/ml) }\end{array}$ & $\begin{array}{c}\text { Blood } \\
\text { C/S }\end{array}$ & $\begin{array}{c}\text { Urine } \\
\text { C/S }\end{array}$ & $\begin{array}{c}\text { Sputum } \\
\text { C/S }\end{array}$ & $\begin{array}{c}\text { Pus } \\
\text { C/S }\end{array}$ & $\begin{array}{c}\text { Ascitic } \\
\text { fluid C/S }\end{array}$ \\
\hline$<0.5$ & 0 & 0 & 0 & 0 & 0 \\
\hline$>0.5<2$ & 2 & 1 & 1 & 0 & 0 \\
\hline$>2<10$ & 2 & 1 & 1 & 1 & 0 \\
\hline$>10$ & 3 & 3 & 2 & 2 & 1 \\
\hline Total & 7 & 5 & 4 & 3 & 1 \\
\hline
\end{tabular}

Table 15: Culture and PCT in relation to severity of sepsis

\begin{tabular}{|ll|c|c|c|c|}
\hline & $<\mathbf{0 . 5}$ & $\mathbf{> 0 . 5 , < 2}$ & $\mathbf{> 2 , < 1 0}$ & $>\mathbf{1 0}$ \\
\hline No growth Sepsis & 3 & 8 & 6 & 2 \\
\hline & Severe sepsis & 0 & 2 & 2 & 3 \\
\hline & Septic shock & 0 & 0 & 2 & 2 \\
\hline Growth & Sepsis & 0 & 1 & 1 & 2 \\
\hline present & Severe sepsis & 0 & 1 & 2 & 4 \\
\hline \multicolumn{2}{|r|}{ Septic shock } & 0 & 2 & 2 & 5 \\
\hline
\end{tabular}

Table 16: Severity of sepsis \& Diagnostic value of Procalcitonin

\begin{tabular}{|c|c|c|c|}
\hline Procalcitonin & Sepsis/ SIRS & Severe Sepsis & Septic shock \\
\hline (ng/ ml) & & & \\
\hline$\varangle 0.5$ & $3(6 \%)$ & 0 & 0 \\
\hline$>0.5<2$ & $9(18 \%)$ & $3(6 \%)$ & $2(4 \%)$ \\
\hline$>2<10$ & $7(14 \%)$ & $4(8 \%)$ & $4(8 \%)$ \\
\hline$>10$ & $4(8 \%)$ & $7(14 \%)$ & $7(14 \%)$ \\
\hline
\end{tabular}

Table 17: SOFA score and Severity of sepsis

\begin{tabular}{|l|c|}
\hline Severity & Mean SOFA Score \\
\hline SIRS, Sepsis & 4.9 \\
\hline Severe Sepsis & 10.2 \\
\hline Shock & 11.8 \\
\hline
\end{tabular}

Table 18: PCT V/s SOFA Correlation

\begin{tabular}{|l|c|}
\hline Procalcitonin(ng/ $\mathbf{m l})$ & Mean SOFA Score \\
\hline$<0.5$ & 6 \\
\hline $0.5-2$ & 8.4 \\
\hline $2-10$ & 10.6 \\
\hline$>10$ & 12.2 \\
\hline
\end{tabular}

Table 19: PCT V/s SOFA V/s ESR Correlation

\begin{tabular}{|l|c|c|}
\hline Procalcitonin(ng/ ml) & Mean SOFA Score & Mean ESR \\
\hline$<0.5$ & 6 & 30 \\
\hline $0.5-2$ & 8.4 & 50 \\
\hline $2-10$ & 10.6 & 42 \\
\hline$>10$ & 12.2 & 53 \\
\hline
\end{tabular}

Table 20: PCT V/s M ortality Correlation

\begin{tabular}{|c|c|c|c|}
\hline Procalcitonin & Frequency & No. of deaths & \% mortality \\
\hline (ng/ $\mathbf{m l})$ & $(\mathbf{n = 5 0})$ & $(\mathbf{n = 2 0})$ & \\
\hline$<0.5$ & 3 & 0 & 0 \\
\hline $0.5-2$ & 14 & 4 & $20 \%$ \\
\hline $2-10$ & 15 & 5 & $25 \%$ \\
\hline$>10$ & 18 & 11 & $55 \%$ \\
\hline
\end{tabular}

\section{Conclusions:}

Summarily, the observations and results from the present study confirm that Procalcitonin(PCT) is a promising marker of sepsis especially at the time of admission itself among critically ill patients.

PCT measurement appears to be a better predictor to distinguish patients with sepsis and patients without sepsis when compared to ESR.

PCT is an excellent marker providing the additive effect to improve the predictive power for diagnosing sepsis, for assessing severity of sepsis, and also for predicting the outcome/prognosis especially during the first 24 hours of admission.

It is all about "confidence" and confidence comes through PCT while managing critically ill patients, as a quick PCT estimation by BRAHMS- PCT Q test (reports available within 30 minutes and is independent of observer bias) is a boon.

Thus from the present study we conclude that :

I Addition of procalcitonin (PCT) into the workup of critically ill patients with suspected sepsis will aid definitive diagnosis and also help in quick complex patient management.

I Procalcitonin(PCT) is not a myth nor a hype and definitely not an innocuous laboratory curiosity but it is a hard reality and is an answer to sepsis dilemma.

\section{References:}

1. Snider RH Jr, Nylen ES, Becker KL. Procalcitonin \& its component peptides in systemic inflammation, immunochemical characterization. Investing M ed 1997; 45: 552-560.

2. Chaudhury A, Rao TV. Bacteraemia in a tertiary care urban hospital in south India. Indian J Pathol M icrobiol 1999; 42: 317-20.

3. Brun-Buisson C Doyon F, Carlet J, et al. -incidence, risk factor, and outcome of severe sepsis and septic shock in adults: a multicenter prospective study in intensive care units. JAM A 1995; 274: 968-974.

4. Calandra T, Cohen J et al 'The international sepsis forum consensus 
conference on definition of infection in the intensive care unit"; Critical care medicine 2005; 3: 1538-1548

5. Stephen Harbarth S, Holeckova K, Froidevaux C et al: Diagnostic value of procalcitonin, $1 \mathrm{~L}-6$ \& IL-8 in critically ill patients with suspected sepsis, Am J Respir, Crit Care M ed.2001; 164(3): 396-402.

6. Vincent JL, M oreno R, Takala J et al. The SOFA (Sepsis-related Organ Failure Assessment) score to describe organ dysfunction/failure. Intensive Care M ed 1996; 22: 707-710.

7. Todi S, Chatterjee S and Bhattacharyya, Epidemiology of severe sepsis in India from 27th International Symposium on Intensive Care and Emergency M edicine, Critical Care 2007, 1I (Suppl 2): P65.

8. Mylen ES, Snider RH Jr. Thompson KA, Rohatgi P, Becker KL. Pneumonitis associated hyperprocalcitonnemia. Am J Med Sci 1996; 312: 12-18

9. Brunkhorst FM Wegscheider K, Forycki ZF , Brunkhorst R. Procalcitonin for early diagnosis and differentiation of SIRS, sepsis, severe sepsis, and septic shock.. Intensive care med 2000, 26 (suppl2): 148- 152

10. Meisner $M$, et al. "Comparison of procalcitonin \& CRP plasma Concentrations at different SOFA scores during the course of sepsis and M ODS". Crit Care M ed. 1999; 3: 45-50.

11. Chan YL et al. Procalcitonin as a marker of bacterial infection in Emergency department Crit Care M ed. 2004; 8(1): R12-R20.

12. Kasper. D.L. etal.. Harrisons principles of internal medicine $17^{\text {th }}$ edition New York: M eGraw Hill. 2; 1689-1701

13. Meisner M: Procalcitonin - A new Innovate infection parameter. Biochemical \& clinical aspects. Thieme Stuttgart, New York 2000, ISBN: 3-13-105503-0.

14. Becker KL, et al. Clinical review of Procalcitonin and the calcitonin gene family of peptides in inflammation, infection \& sepsis: J Clin Endocrinol M etab. 2004; 89: 1512-1525.

15. Muller B, Becker KL. Procalcitonin how a hormone became a marker and mediator of sepsis. swiss med weekly 2001; 131: 596-602.
16. Whang KT et al, Serum procalcitonin precursors in sepsis and systemic inflammation.J Clin Endocrinol M etab. 1998; 83: 3296-3301.

17. Meisner. Pathobiochemistry and clinical use of procalcitonin. Clin Chem 2002; 323: 17-29.

18. Meisner M, et al. Clinical experiences with a new, semiquantitative solid phase immunoassay for rapid measurement of procalcitonin. Clin. Chem. Lab. M ed.2000; 38 (IG): 989-995

19. Simon L, Gauvtn $f$ Anre K, Saint-Louis P, Lacroix J. Serum Procalcitonin $\&$ CRP levels as markers of bacterial infection. A systemic review \& meta-analysis. Clin Infect Dis 2004; 39: 206-217.

20. Cincent J-L. Procalcitonin : The marker of sepsis Crit Care M ed. 2000; 28: 1226-1227.

21. M uiler B, Becker $\mathrm{KL}$, Schachfnger $\mathrm{H}$, et al. Calcitonin precursor are reliable markers of sepsis in a medical intensive care unit. Crit Care Med. 2000; 28: 977-983

22. Brunkhorst FM, Eberhard OK, Brunkhorst R: Discrimination of infectious and noninfectious causes of early acute respiratory distress Syndrome by procalcitonin. Crit Care M ed 1999; 27: 2172-2176.

23. Gian Paolo Castelli, et al. "Procalcitonin and CRP during SIRS, sepsis and organ dysfunction". Crit Care M ed, 8: 234-R242.

24. American College of Chest Physicians/Society of Critical Care M edicine Consensus Conference: definitions for sepsis and organ failure and guidelines for the use of innovative therapies in sepsis. Critical Care Med 1992; 20: 864-874.

25. M oreno R, Vincent JL, M atos R, et al. The use of maximum SOFA score to quantify organ dysfunction/failure in intensive care. Results of a prospective multicentre study. Intensive Care M ed 1999; 25: 686-696.

26. Martin GS, ManninoDM, Eaton.S and Moss.M 2003; "The Epidemiology of sepsis in United States from 1979 through 2000; N engj.Med 348; $1524-5446$

27. Sands KL, Bates DW, Lanken PW, et al. Epidemiology of sepsis syndrome in 8 academic medical centers. JAM A 1997; 278: 234-240. 